\title{
TOPLU BESLENME İÇİN MENÜ PLANLAMA KARAR DESTEK SİSTEMİ GELİŞTİRİLMESİ VE UYGULANMASI
}

\author{
Adil BAYKASOĞLU, Damla TAŞKIRAN, Hatice Gökçen AKKOYUN \\ Dokuz Eylül Üniversitesi, Mühendislik Fakültesi, Endüstri Mühendisliği Bölümü, 35397, Tınaztepe, Buca, İzmir \\ adil.baykasoglu@deu.edu.tr, damla.taskiran@yahoo.com, haticegokcen.akkoyun@gmail.com
}

(Geliş/Received: 02.03.2015; Kabul/Accepted: 15.10.2015)

\begin{abstract}
ÖZET
Toplu beslenme sistemleri için aylık menü planlama, sağlıklı beslenme; kısıtlı bütçe; mevsimselliğin tedarike etkisi; kısıtlı sürede toplu yemek çıkarabilme kapasitesi; tüketici memnuniyeti; planlanan yemeklerin dönemler arasındaki etkileşimi; birlikte sunulan yemeklerin uyumu; ön hazırlık gerektiren yemeklerin uzun süren tatillerden sonra planlamaması gibi durumları dikkate almayı gerektiren çok karmaşık bir süreçtir. Literatürde sözü edilen faktörleri eș zamanlı olarak dikkate alan bir bilimsel çalıșmaya rastlanmamıștır. Uygulamada ise menü planlama çalışması deneyimlerle elde edilen bilgilere dayanmakta ve sistemleşmiş bir yapı bulunmadığından planlama sonunda gözden kaçırılan pek çok hususa rastlanabilmektedir. Literatürde ve uygulamada tespit edilen bu eksiklikleri karşılamak amacıyla çok sayıda faktörü eş zamanlı dikkate alan ve yıl boyunca kullanılabilen bir karar destek sistemi tasarlanmıştır. Tasarlanan karar destek sisteminin uygulama ve test çalışmaları DEÜ Kantin - Kafeteryalar ve Beslenme Şube Müdürlüğü’nde yapılarak elde edilen sonuçlar sunulmuştur.
\end{abstract}

Anahtar Kelimeler: Menü planlama, karar destek sistemi, çok amaçlı matematiksel programlama, tamsayılı programlama

\section{DEVELOPMENT OF A MENU PLANNING DESICION SUPPORT SYSTEM FOR MASS CATERING WITH AN APPLICATION}

\begin{abstract}
Monthly menu planning in mass catering is a complex decision problem with many objectives, constraints and factors like healthy eating, limited budget, seasonality effects, capability of producing food for thousands of people within a limited time, customer satisfaction, interactions between periods of planned meals, harmony of meals which are served together, preparation constraints etc. In the scientific literature, there is no serious study which simultaneously considers all of the aforementioned factors simultaneously within a decision support framework. In practice, menu planning studies are usually based on information gathered from experts and previous practices. Due to lack of a systematic procedure it is almost impossible to satisfy most of the objectives and constraints. In the present work, first time in the literature an integrated decision support system is designed which considers many operational and practical constraints and objectives simultaneously. A real life application of the proposed decision support system is also carried out at DEU Canteen-Cafeterias Department with real data for model verification and validation.
\end{abstract}

Keywords: Menu planning, decision support system, multi objective mathematical programming, integer programming

\section{GİRIŞ (INTRODUCTION)}

Menü; tüketicilerin gereksinim ve/veya talepleri doğrultusunda tasarlanan yiyecek ve içeceklerin bir planıdır. Genellikle menü planlama ve geliştirme az anlaşılan ve en çok ihmal edilen bir konudur [1]. Toplu beslenme sistemlerinin başarısı yiyeceklerin seçimine ve servisine, dolayısıyla menüye ve menü planlamasına bağlıdır [2]. Bu sistemlerde menü planlama çalıșması: sağlıklı beslenme; mevsimselliğin tedarike etkisi; kısıtlı bütçe; çalışan/tüketici memnuniyeti; planlanan yemeklerin dönemler arasındaki etkileşimi; birlikte sunulan yemeklerin renk, kıvam, tat olarak uyumu; uzun süren tatillerden 
sonra ön hazırlı gerektiren yemeklerin planlanamaması ve doğrudan alım gerektiren istisnai durumlar gibi konulardan etkilenen karmaşık bir karar sürecidir. Söz konusu problem bilimsel yazında temel hali ile çeşitli yöntemler kullanılarak incelenmiştir. Soden vd. [3] doğrusal programlama, Sklan vd. [4] ile Şenol [5] karma tam sayılı doğrusal programlama; Anderson vd. [6] doğrusal ve hedef programlama; Balintfy vd. [7] doğrusal olmayan programlama ve dal - sınır algoritması; Ediz vd. [8] hedef programlama; Mamat vd. [9], Mamat vd. [10], Oruç vd. [11] bulanık doğrusal programlama; Oruç [12] bulanık hedef programlama yöntemlerini kullanarak çözüm önerilerinde bulunmuşlardır. $\mathrm{Bu}$ çalışmalar diyet ve menü planlama problemlerinde dikkate alınması gereken temel prensipleri dikkate alan model önerilerinde bulunmakla birlikte, kısıtlı sürede toplu yemek hazırlama sürecinde karşılaşılan güçlükler (çalışan memnuniyeti), tüketici geri bildirimi ve uzun süren tatil dönüşlerinde ön hazırlık gerektiren yemeklerin sunulamaması gibi menü planlama sürecinin uygulanabilirliğini doğrudan etkileyen unsurları göz ardı etmiş ve birlikte sunulan yemekler arasındaki kıvam ve renk uyumları gibi detaylara model yapısı içerisinde (amaç ve/veya kısıt olarak) yer vermemişlerdir. Ayrıca önerilen modellerde kullanılan yöntemler çeşitli olsa da, tüm modeller günlük, haftalık veya aylık çözümler üretecek şekilde tasarlanmıştır. $\mathrm{Bu}$ durum menü planlama gibi mevsimlere bağlı olarak veri tabanı (yemek havuzu) ve tüketici tercihlerinden etkilenen kısıtları (yazları ferahlatıcı, kışları enerji verici yemek tercihi gibi) değişen problemlerde her plan dönemi için yeni bir model tasarlama sorununa yol açmakta ve tasarlanan modellerin gerçek hayattaki uygulanabilirliğini azaltmaktadır. Mevcut çalışmanın temel amacı toplu beslenme sistemlerinde aylık menü planlamasında kullanılmak üzere yukarıda ifade edilen tüm etmenleri eş zamanlı dikkate alarak yıl boyunca bütünleşik çalışabilen bir karar destek sistemi tasarlamaktır. Tasarlanan karar destek sistemi dört temel bileşenden oluşmaktadır: "Veri Tabanı", "Model", "Makro Tabanlı Kullanıcı Arayüzü" ve "Karar Birimi” (Bkz. Şekil 1). "Veri Tabanı" modellemede kullanılan parametrelerden oluşmaktadır. "Makro Tabanlı Kullanıcı Arayüzü” ile modelleme bilgisi kısıtlı son kullanıcıların alışkanlıkları dikkate alınarak uzun vadede değişim göstererek planlamayı etkileyen parametreleri hesaplayabilen bir bilgisayar programı geliştirilmiştir. Menü planlama sürecinde dikkate alınması gereken faktörleri eş zamanlı dikkate alan bütünleşik bir "Model” oluşturulmuş ve "Karar Birimi" ile senaryo analizleri yapilarak modelin gerekli hallerde revize edilmesine olanak tanınmıştır. Çalışmanın gerçek veriler ile doğrulanması ve uygulanması "Dokuz Eylül Üniversitesi KantinKafeteryalar ve Beslenme Şube Müdürlüğü’nde gerçekleştirilmiştir (Çalışmanın yapıldı̆̆ı yer bundan sonraki kısımlarda "kurum" olarak ifade edilecektir.). Kurum toplu beslenme sistemini uzun yıllardır uygulamakta olup, yemekhanelerinde öğle yemeği için günde ortalama 6000 kişiye dört kap set seçimsiz yemek sunmaktadır. Çalışma kurum görevlilerinin yoğun desteği ile 18 aya yakın bir çalışma sürecinde gerçekleştirilmiş olup sistemin uygulamaya alınması için gerekli olan faaliyetler halen devam etmektedir.

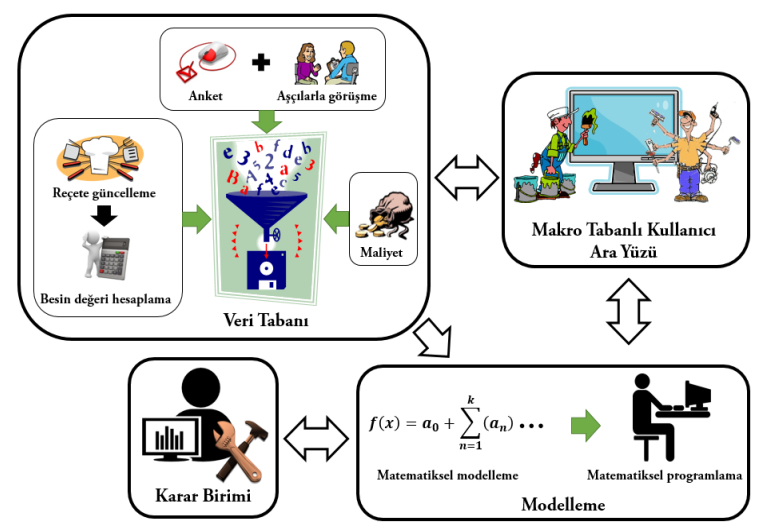

Şekil 1. Karar destek sistemi (Decision support system)

\section{KARAR DESTEK SISTEM TASARIMI (DECISION SUPPORT SYSTEM DESIGN)}

Sağlıklı bir karar destek sistemi oluşturmak için kurumdaki mevcut iş akışı ve karar alma süreçleri detaylı bir şekilde incelenmiştir. Şube müdürü, diyetisyen ve gıda teknikeri ile yapılan görüşmelerden edinilen bilgilerle aylık menü listesi hazırlık aşamasından mutfağın yiyecekleri kabulüne kadar olan süreç ek bölümünde Şekil E1'de gösterilmiştir.

\subsection{Veri Tabanı (Data Base)}

\subsubsection{Aylık yemek havuzları oluşturma (Creating the pool of monthly meal)}

Yiyecek bulma olanağı mevsimlere göre ayrıcalık gösterir. Yazın bulunan bir yiyecek kışın, kışın bulunan yazın bulunamayabilir. $\mathrm{Bu}$ nedenle menü mevsimlere göre değişik biçimde hazırlanır. Menüdeki mevsimsel değişikliklerden ise en çok meyve ve sebzeler etkilenmektedir. Bu gün seracılığın gelişmesi ile pek çok meyve ve sebzeyi mevsimi dışında bulma olanağı vardır. Ancak bu tür meyve ve sebzeler, tabii olanlara oranla besin değeri ve kalitesi daha düşüktür. Ayrıca hem daha lezzetsiz hem de daha pahalıdır [5]. Menü listesinde çıkma ihtimali olan yemekler, matematiksel modellemede kullanılacak karar değişkenlerini etkilemektedir. Meyve ve sebzelerin mutfaklara tedariki aylara göre değiştiğinden, aylık menü listesi dolayısıyla tasarlanan modelin karar değişkenleri de aylara göre değişmektedir. $\mathrm{Bu}$ nedenle yemek havuzu oluşturulurken uygulama yapilan kurumun tedarikçilerle yaptığı anlaşma koşulları dikkate alınarak her ay için ayrı yemek havuzu oluşturulmuş ve havuzdaki yemek reçeteleri (tarifler) güncellenmiştir. 


\subsubsection{Porsiyon başına besin değerlerinin hesaplanması (Calculation of nutrition values per meal)}

Menü planlama çalışmasında en önemli noktalardan biri dengeli beslenme kısıdının sağlanmasıdır. $\mathrm{Bu}$ nedenle tüm yemeklere ait porsiyon başına besin değerlerinin hesaplanması gerekmektedir. Besin değerleri birlikte çalışılan kurumdaki diyetisyenler ile iletişime geçilerek hesaplanmış ve veri tabanına aktarımı sağlanmıştır. FAO/WHO (Gıda ve Tarım Örgütü/Dünya Sağlık Örgütü) standart değerleri ise dengeli beslenme kısıdının sınır değerleri kabul edilmiştir.

\subsubsection{Yemeklerin gruplandırılması (Bundling of meals)}

Menüler çok çeşitli şekillerde sınıflandırılabilir. Ancak genellikle çalışan personele hizmet veren toplu beslenme sistemlerinde "set-seçimsiz menüler" kullanılır. Seçimsiz menüler set şeklindedir ve yemek seçim şansı tanımamaktadır. Bu menülerde yer alan yemek sayısı $3-4$ kapla sinırlandırılır [8]. DEÜ Yemekhaneleri'nde set - seçimsiz dört kap yemek sunulmaktadır. $\mathrm{Bu}$ nedenle uygulama yapilan kurumun diyetisyeni ile görüşülerek yemekler Tablo 1'de gösterildiği gibi dört gruba ayrılmıştır (Tablodaki kısaltmalar matematiksel modelde kullanılmıştır):

Tablo 1. Yemek gurupları ve kisaltmaları (Foods groups and their abbreviations)

\begin{tabular}{|c|l|}
\hline Gruplar & \multicolumn{1}{|c|}{ İçerdiği Yemekler } \\
\hline $\begin{array}{c}\text { 1.Grup } \\
\text { (g1) }\end{array}$ & $\begin{array}{c}\text { Balık (ba), Etli Dolma (ed1), Etli Kurubaklagil } \\
\text { (ek1), Etli Sebze (es1), Etsiz Kurubaklagil (ek2), } \\
\text { Hindi (h), Kebap (ke), Köfte (kof), Mantı (m1), } \\
\text { Parçalı Et (pe), Tavuk (t), Yumurtalı Yemek (y1) }\end{array}$ \\
\hline $\begin{array}{c}\text { 2.Grup } \\
\text { (g2) }\end{array}$ & $\begin{array}{l}\text { Börek (bo), Çorba (c1), Makarna (m2), Pilav } \\
\text { (p1), Etsiz Dolma (ed2), K1zartma (ki), Etsiz } \\
\text { Sebze (es2) }\end{array}$ \\
\hline $\begin{array}{c}\text { 3.Grup } \\
\text { (g3) }\end{array}$ & $\begin{array}{l}\text { Ayran (a), Cacık (c), Piyaz (p2), Salata (s), } \\
\text { Yoğurt (y2), Turşu (t) }\end{array}$ \\
\hline $\begin{array}{c}\text { 4.Grup } \\
\text { (g4) }\end{array}$ & $\begin{array}{c}\text { Çorba (c2), Komposto (kom), Meyve (m3), Sütlü } \\
\text { ve Şerbetli Tatlı (st), Aşure (a), Kabak Tatlısı (kt) }\end{array}$ \\
\hline
\end{tabular}

\subsubsection{Maliyetlerin hesaplanması (Calculations of costs)}

Planlanan ve planlanma ihtimali olan yemeklere ait malzemelerin birim fiyatları ve reçete değerleri MS Excel ortamında porsiyon başına maliyetler cinsinden hesaplatılıp elde edilen değerlerin modelde kullanılacak parametrelerin bulunduğu veri tabanına aktarılmasını sağlayacak bir yapı geliştirilmiştir.

\subsection{5 Çalışan memnuniyet katsayısı (Staff satisfaction index)}

Toplu beslenme sistemlerinde kısıtlı süre içerisinde, planlanan yemeklerin sunuma hazır hale getirilmesi oldukça zahmetli bir iştir. Bu nedenle menü planlama sürecinde her bir yemeğin ne kadarlık çabayla hazırlanabileceği ve günde ortalama ne kadar çaba gerektiren yemek sunumu yapılabileceği sorularına yanıt aranmıştır. Her bir yemek için harcanan çaba miktarını puanlayabilmek için toplam 7 mutfağ 1 bulunan kurumun tüm yemekler hakkında ayrıntılı bilgiye sahip 3 mutfak baş aşçısı ile yüz yüze görüşmeler yapılarak yemeklere 10 üzerinden puan verilmiştir. Hazır yemekler (ayran, şerbetli tatlı gibi) için 10 puan verilirken ön hazırlık, pişirme, sunuma hazırlık gerektiren yemeklere harcanan çaba arttıkça verilen puan azaltılmıştır. Mutfaklarda günde ortalama ne kadar çaba gerektiren yemek sunumu yapılabileceğini tespit edebilmek için "Delphi Tekniği” kullanılmıştır. Bir görüş birliği sağlama aracı olarak ifade edilen Delphi yöntemi bir problem durumuna farklı açılardan bakan bireylerin ya da grupların yüz yüze gelmeden uzlaşmalarını amaçlayan bir yöntemdir [13]. Delphi tekniği kullanılarak bir problem durumuna farklı açılardan bakan bireylerin ve grupların görüş birliğine (consensus) ulaşmaları amaçlanır [14].

$\mathrm{Bu}$ çalışma da önce aşçıbaşılarının her birinden, diyetisyenden, gida teknikerinden ve şube müdüründen ortalama bir puan istenmiş sonra ortak bir puanda karar k1lınana kadar puan istenmeye devam edilmiştir. Yapılan görüşmeler sonunda mutfaklarda günde ortalama 20 puanlık yemek çıkarılabileceğine karar verilmiştir.

\subsubsection{Müşteri memnuniyet katsayısı (Customer satisfaction index)}

Müşteri memnuniyet katsayısını belirleyebilmek amaciyla "anket" yöntemi kullanılarak DEÜ yemekhanelerini kullanan tüketici kitlesi ile etkileşime geçilmiştir. Mevcut çalışma kapsamında uygulaması yapilan ankete http://web.deu.edu.tr/baykasoglu/deumenu.pdf adresinden erişilebilir. Örneklem büyüklükleri şu şekilde belirlenmiştir. $p$ : bayan - erkek oran1 $(0,58) ; \alpha$ : önem düzeyi $(0,05)$; E: göz ardı edilebilecek maksimum hata $(0,05)$ olmak üzere,

$p(1-p)\left(\frac{Z \frac{\alpha}{2}}{E}\right)^{2}$

Eşitlik 1 kullanılarak \%95 güven düzeyinde, $\% 5$ yanılma payıyla 6000 kişilik bir kitle hakkında istatistiksel analiz yapabilmek için örneklem olarak 624 kişiye anket uygulanması gerektiği anlaşılmıştır. Yemekhaneleri kullanan 6000 kişilik kitlenin heterojen bir yapı oluşturduğu tespit edilmiş ve oranlı tabakalı örnekleme tekniği kullanılmıştır. Tabakalı örnekleme, evrendeki alt grupların belirlenip bunların evrende var oldukları aynı oranlarıyla örneklemde temsil edilmelerini sağlayan bir örneklem seçme tekniğidir [15]. Bu çalışma da hedef kitle tabaka adı 
verilen ve daha homojen olan "Personel" ve "Öğrenci" adlı iki gruba ayrılmıştır. Personel adlı grup kitlenin \%16’sını, öğrenci adlı grup ise kitlenin $\% 84$ 'ünün oluşturmaktadır. $\mathrm{Bu}$ nedenle 624 anketin \%16's1 personel grubuna, \%84'ü ise öğrenci grubuna uygulanmıştır.

Öğle yemeğinde porsiyon başına sağlanması gereken besin değerleri: \%95 güven düzeyinde, $\% 5$ yanılma payıyla uygulanan anketlerden elde edilen sonuçlara göre örneklemin \%62'si günde 3 öğünden fazla beslenmektedir. $\mathrm{Bu}$ nedenle kurum diyetisyeni ile görüşülerek hedef kitlenin FAO-WHO standartlarına göre günlük alması gereken besin değerlerinin 2/5'inin öğle yemeğinde karşılanması hedeflenmiştir.

Müşteri memnuniyet katsayısı: $r_{j}$, kriterin grup içindeki sıralaması olmak üzere,

$w_{i}=\left(\frac{1}{r_{j}}\right) / \sum \frac{1}{r_{k}}$

Eşitlik 2'deki “Kriterleri Karşılıklı Sıralama” formülü kullanılarak, yiyecek gruplarını sıralayan anket verileri müşteri memnuniyet katsayısına dönüştürülmüştür.

\subsection{Kullanıcı Arayüzü (User Interface)}

Uzun dönemli çalışan bütünleşik bir sistem tasarlayabilmek için, menü planlama çalışmasını etkileyen çeşitli parametreleri dikkate alarak sistemi adapte edebilen bir yapıya ihtiyaç vardır. Kısa dönemli planlama da sabit olarak düşünülen bazı parametreler uzun dönemli modeller de değişebilmektedir. $\mathrm{Bu}$ nedenle her planlama öncesinde bu değişkenlerin hesaplanıp elde edilen sonuçların modele parametre olarak aktarılması gerekmektedir. Uygulama yapılan kurumun menü planlama çalışmasını süreç boyunca etkileyen değişkenler, yapılan görüşmeler ve analizler ile belirlenmiştir. $\mathrm{Bu}$ değişkenler: planlama yapılacak ayın "iş günü sayısı”; tatil dönüşleri; "18 Mart'ın denk geldiği iş günü; "Aşure Ayı"; doğrudan alım durumu ve bütçedir. $\mathrm{Bu}$ değişkenlerin değişim periyotları farklı olmakla birlikte, tamamı menü planlama çalışması yapılmadan önce sabit hale gelmektedir. $\mathrm{Bu}$ nedenle kullanıcı ile etkileşime geçerek tüm bu değişkenleri hesaplayan, hesapladığı bu değerleri ve planlama yapacağ tabanını matematiksel programa parametre olarak aktaran ve programın elde ettiği çözümü aylık menü listesi haline getirip yazıcıya gönderen makrolar Visual Basic dili kullanılarak Excel ortamında programlanmıştır.

Makro programlama bilmeyen kullanıcıların değişken bilgilerini güncelleştirme işlemini kolaylaştırmak amaciyla Excel programı üzerinden kullanıcı alışkanlıklarına uygun olarak Şekil 2'deki "kullanıcı arayüzü” geliştirilmiştir.

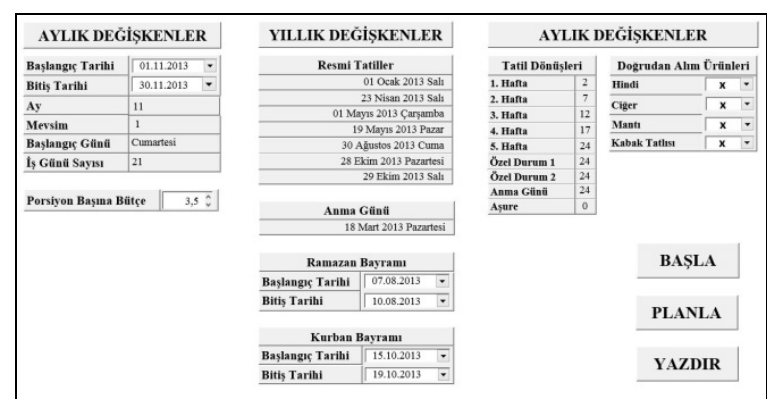

Şekil 2. Kullanıcı arayüzü ekran görüntüsü (Screen shot of user interface)

\subsection{Model (Model)}

\subsubsection{Matematiksel programlama modeli (Mathematical programming model)}

Matematiksel programlama modelinde karar değişkenleri her ay için (yemek havuzu*iş günü sayısı) adet yemekten oluşmaktadır. Müşteri/çalışan memnuniyet katsayısı; besin değerleri, porsiyon başına maliyet ve değişken değerleri ise modelin parametrelerini oluşturmaktadır. Geliştirilen matematiksel modelde;

Karar Değişkenleri: $\boldsymbol{A}_{i j}$ : i. sıradaki yemek çeşidinin j. gün çıkıp çıkmama durumu; Indisler: $i$ : yemekleri ifade eden indis, $\boldsymbol{j}$ : günleri ifade eden indis;

Parametreler: CalisanMem $\mathbf{M}_{\mathrm{i}}$ : i. suradaki yemeğe ait çalışan memnuniyet katsayısı, $\boldsymbol{E}_{\boldsymbol{i}}:$ i. sıradaki yemeğin içerdiği enerji miktarı, $\boldsymbol{K}_{i}:$ i. sıradaki yemeğin içerdiği Kalsiyum miktarı, Maliyet $_{i}$ : i. suradaki yemeğin

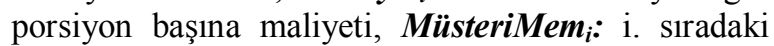
yemeğe ait müşteri memnuniyet katsayısı, $N_{i}:$ i. sıradaki yemeğin içerdiği Niasin miktarı, $\boldsymbol{V} \boldsymbol{A}_{\boldsymbol{i}}$ : i. sıradaki yemeğin içerdiği Vitamin A miktarı, $\boldsymbol{V} \boldsymbol{B} \boldsymbol{1}_{\boldsymbol{i}}$ : i. sıradaki yemeğin içerdiği Vitamin B1 miktarı, $\boldsymbol{V} \boldsymbol{B} \boldsymbol{2}_{\boldsymbol{i}}$ : i. sıradaki yemeğin içerdiği Vitamin B2 miktarı, $\boldsymbol{V} \boldsymbol{C}_{\boldsymbol{i}}$ : i. sıradaki yemeğin içerdiği Vitamin $\mathrm{C}$ miktarı $\mathbf{\Omega}$ : Ortalama ne kadarlık puan değerinde yemek çıkarabileceğini gösteren parametre;

Değişkenler: agun: 18 Mart anma gününün denk geldiği iş günü, asure: aşure ayında olup olmama durumu, ay: kaçıncı ayda olunduğunu ifade eden değişken, butce: porsiyon başına günlük bütçe, dn: negatif sapma değişkeni, dp: pozitif sapma değişkeni, mev: mevsimleri ifade eden değişken, $\boldsymbol{t} d$ : iki ya da daha uzun süren tatil dönüşüne denk gelen iş günü, top: menü planlama yapılacak iş günü sayısı;

Ifadeler: az: tüketiciler tarafindan az tercih edilen yemekler, benzer: benzer malzemelere sahip yemekler, dalim: doğrudan alım ürünleri, kuru: kuru yemekler, on: ön hazırlık gerektiren yemekler, ps: planlama sıklığı, renk: benzer renge sahip yemekler, ts: tavuk suyu içeren yemekler, $\boldsymbol{x}$ : yemek havuzundaki her hangi bir yemek, $y$ : x yemeği ile birlikte sunulamayan yemek, $\boldsymbol{y} \boldsymbol{h}$ : yemek havuzunda 
bulunan tüm yemekler, z: ana malzemesi aynı olan yemekler olmak üzere, "0-1 tam sayılı çok amaçlı matematiksel programlama" yöntemi kullanılan modelin iki temel amacı vardır: çalışanların porsiyon başına gösterebileceği performansa ait negatif ve pozitif sapma toplamını minimize etmek ve tüketici memnuniyetini maksimize etmek. Bu amaçlar kurum çalışanların istekleri doğrultusunda geliştirilmiştir.

\section{Birinci amaç fonksiyonu:}

$\min z=\left(d_{p}+d_{n}\right)$

$\sum_{i \in y h}\left(\right.$ CalisanMem $\left._{i} * A_{i j}\right)+d n-d p=\Omega, \forall \mathrm{j}$

Eşitlik 4 birinci amaç fonksiyonundaki sapma değişkenlerini hesaplamak için kullanılmaktadır. Bu eşitlik amaç programlamadaki yumuşak kısıtlar gibi fonksiyon göstermektedir, $d_{p}, d_{n} \geq 0$. Ortalama ne kadarlık puan değerinde performans gösterilebileceğini ifade eden $\Omega$ parametresindeki pozitif yöndeki sapmalar menünün ağırlıklı olarak hazır ürünlerden (şerbetli tatlı, ayran vb.) oluşmasına, negatif yöndeki sapmalar ise menünün belirlenen sürede yetiştirilememesine sebep olduğu için çalışanların porsiyon başına gösterebileceği performansa ait negatif ve pozitif sapmalar toplamının minimize edilmesi amaçlanmıştır. $\Omega$ parametresinin değeri ise uygulama yapılan kuruma göre farklı değerler alabilir.

Ikinci amaç fonksiyonu:

$\max \mathrm{z}=\sum_{j=1}^{t o p} \sum_{i \in y h}\left(\right.$ MüsteriMem $\left.{ }_{i} * A_{i j}\right)$

İkinci amaç fonksiyonu ile müşteri memnuniyetinin maksimize edilmesi amaçlanmıştır. Çok amaçlı programlamada sıklıkla kullanılan $\epsilon$-kısıt $(\epsilon-$ constraint) yaklaşımı ile model önce birinci amaç fonksiyonu için çözülmüş sonra bu amaç modele kısıt olarak eklenip ikinci amaç fonksiyonu maksimize edilmeye çalışılmıştır.

Kısıtlar: Karar değişkenlerinin 0 veya 1 tamsayı değerini alma durumu:

$A_{i j}=0$ veya $1, \forall i j$

Bütçe kısıtı: Başarılı bir menü planı için menü maliyetinin ve bu maliyetin kurum bütçesi içindeki yerinin çok iyi belirlenmesi ve kontrolünün etkin bir biçimde yapılması gerekir. Yiyecek için harcanan para her kurumda farklıdır [5]. Uygulama yapılan kurumda tüketicilerin porsiyon başına ödediği ücret miktarından porsiyon başına gaz ücreti ve ekmek ücreti düşüldükten sonra elde edilen miktar, porsiyon başına günlük bütçe olarak kabul edilmektedir. $\mathrm{Bu}$ miktar ile iş günü sayısı çarpılarak porsiyon başına aylık bütçe miktarı hesaplanmaktadır. Menü listesindeki yemekler için yapılacak aylık harcamanın aylık bütçeyi aşamayacağını gösteren kısıt şu şekilde ifade edilmiştir:

$\left(\sum_{j=1}^{t o p} \sum_{i \in y h}\left(\right.\right.$ Maliyet $\left.\left._{i} * A_{i j}\right)\right)-($ butce $*$ top $) \leq 0$

Menülerde kap sayısını dikkate alma durumu:

$\sum_{i \in y h}\left(A_{i j}\right)=4, \quad \forall j$

Kurumda günde porsiyon başına dört kap yemek sunulmaktadır. Bu nedenle grup sayısı dört alınmış ve yemek havuzundaki yemekler dört gruba ayrılmıştır. Her kap için her gruptan bir adet yemek seçme kısıtı ise eşitlik 6 kullanılarak ifade edilmiştir.

$\sum_{i \in g 1}\left(A_{i j}\right)=1 ; \sum_{i \in g 2}\left(A_{i j}\right)=1 ; \sum_{i \in g 3}\left(A_{i j}\right)=$ $1 ; \sum_{\in g 4}\left(A_{i j}\right)=1, \forall j$

FAO-WHO standartlarına göre 19-24 yaş arası orta fiziksel aktivite gösteren kişilerin ekmek hariç ögle yemeği için alması gereken besin değerlerini sağlama kısitlart:

$\sum_{i \in y h}\left(E_{i} * A_{i j}\right) \geq 758 ; \sum_{i \in y h}\left(V A_{i} * A_{i j}\right) \geq 0,240 ;$

$\sum_{i \in y h}\left(V B 1_{i} * A_{i j}\right) \geq 0,38$;

$\sum_{i \in y h}\left(V B 2_{i} * A_{i j}\right) \geq 0,62 ; \sum_{i \in y h}\left(N_{i} * A_{i j}\right) \geq 6,72$;

$\sum_{i \in y h}\left(V C_{i} * A_{i j}\right) \geq 12,0604$;

$\sum_{i \in y h}\left(K_{i} * A_{i j}\right) \geq 162, \quad \forall j$

Ikinci gruptaki çorbaları yalnızca balık veya mantı ile birlikte sunma kisidr: Yemek havuzu gruplara ayrılırken çorbalar dördüncü gruba yerleştirilmiştir. Ancak balıklar geleneksel olarak çorba, salata ve helva ile birlikte; mantı ise çorba, salata, meyve veya salata ile sunulmayı gerektirmektedir. Daha önce matematiksel olarak ifade edilen her kaptan yalnızca bir adet yemek sunma kısıdı ile çelişen bu kısıt balık ve mantı yemeklerinin planlanmasina engel olmaktadır. Geliştirilen matematiksel program ile çelişen kısıtlar özel duruma bağlı olarak gevşetilemediği için ikinci gruba da çorbalar eklenmiş ve aşağıdaki kısıt ile birlikte bu çorbaların yalnızca balık ve mantı ile birlikte planlanması garanti edilmiştir:

$\sum_{i \in g 1 /(b a, m 1)}\left(A_{i j}\right)+\sum_{i \in c 1}\left(A_{i j}\right) \leq 1, \quad \forall j$

$\sum_{i \in(b a, m 1)}\left(A_{i j}\right)+\sum_{i \in g 2 /(c 1)}\left(A_{i j}\right) \leq 1, \quad \forall j$

Birlikte sunulan yemekler arasinda tat uyumu sağlamaya yönelik kusitlar: Bu kategoride yer alan k1sitlar tüketici kitlesinin damak zevkine göre değişiklik gösterebilmekle birlikte genel olarak aşağıdaki şekilde ifade edilebilir:

$\sum_{i \in x}\left(A_{i j}\right)+\sum_{i \in y}\left(A_{i j}\right) \leq 1, \quad \forall j$

İfade 13 kurumun tüketici kitlesinin damak zevki ve kurum istekleri dikkate alınarak düzenlenmiştir. 
Örneğin kurum isteği üzerine ekşi tada sahip turşu ile tatlının birlikte sunulması damak zevkini bozan bir unsur olarak kabul edilmektedir.

Içerik uyumuna ait kısıtlar: Menülerde aynı tür malzeme içeren yemeklerin bir arada bulunmaması tercih edilir [8]. Bu nedenle ana malzemesi aynı olan yemekler birlikte sunulmamalıdır:

$\sum_{i \in Z}\left(A_{i j}\right) \leq 1, \quad \forall j$

$\mathrm{Bu}$ kısıt uygulama yerine ait veri tabanı dikkate alınarak düzenlenmiştir.

Kıvam uyumu kısıdı: Aynı gün içerisinde ikiden fazla kuru yemek çıarılması tüketicilerin yemekleri yemesini zorlaştırmaktadır. $\mathrm{Bu}$ nedenle ikiden fazla kuru yemeğin birlikte sunulması engellenerek tüketici memnuniyetini artırıcı kısıt oluşturulmuştur:

$\sum_{i \in k u r u}\left(A_{i j}\right) \leq 2, \forall j$

Ayran, cacık ve komposto, benzer amaçlarla tüketilen sulu yemeklerdir. Bu nedenle bu yemeklerin birlikte sunulmaları istenmemektedir:

$\mathrm{A}_{(\mathrm{i} \in \mathrm{a}, \mathrm{j})}+\mathrm{A}_{\left(\mathrm{i} \epsilon_{\mathrm{c}, \mathrm{j})}\right.}+\sum_{i \in k o m}\left(A_{i j}\right) \leq 1, \quad \forall j$

Renk uyumu kısıdr: Birlikte sunulan yemeklerin benzer renge sahip olması iştah kapatıcı özelliğe sahip bir durumdur. Yapılan analizler sonucunda bu tür durumlarla karşılaşılan günlerde atık miktarında artış görüldüğü tespit edilmiştir. Bu nedenle yemeklerde renk uyumuna dikkat edilerek planlama hatasına bağlı atık miktarında artış görülme problemi azaltmaya yönelik kısıt geliştirilmiştir:

$\sum_{i \in r e n k}\left(A_{i j}\right) \leq 2, \quad \forall j$

Birlikte sunulabilen veya sunulamayan yemekler için kisitlar: Kurumda tavuk suyu ile yapilan yemekler yalnızca tavuk yemeği çıktığında sunulmaktadır. $\mathrm{Bu}$ nedenle tavuk yemeği çıkmayan günlerde tavuk suyu ile yapılan yemeklerin planlamasını engelleyici bir kısıda ihtiyaç duyulmuştur:

$\sum_{i \in g 1 / t}\left(A_{i j}\right)+\sum_{i \in t s}\left(A_{i j}\right) \leq 1, \quad \forall j$

Tüketicilere uygulanan anket sonuçlarına göre bazı yiyeceklerin tercih oranının düşük olduğu tespit edilmiştir. Toplu beslenme sistemlerinin temel görevi sağlıklı beslenme olduğu için bu yiyeceklerin yemek havuzundan tamamen çıkarılması istenmemektedir. Ancak tüketici memnuniyetini artıracak bazı kısıtlar geliştirilebilir. Örneğin tercih edilme oranı düşük yemeklerin birlikte sunumu engellenebilir:

$\sum_{i \in a z}\left(A_{i j}\right) \leq 1, \quad \forall j$
Yemeklerin planlama sıklığı ile ilgili kısitlar: Tüketiciler tarafindan tercih edilme oranı düşük olan yemeklerin aynı ay içerisinde planlanma sıklığına sınırlandırma getirilerek aylık tüketici memnuniyeti artırılabilir:

$\sum_{j=1}^{t o p} \sum_{i \in a z}\left(A_{i j}\right) \leq \mathrm{ps}$

Benzer malzemelere sahip yemeklerin aylık sıklıklarını sınırlayan kısıt:

$\sum_{j=1}^{t o p} \sum_{i \in \text { benzer }}\left(A_{i j}\right) \leq \mathrm{ps}$

Kurum, tavuk; köfte; etli dolma veya etli sebze; etsiz kurubaklagil veya yumurtalı yemek; etsiz kurubaklagil veya etli kurubaklagil; kebap veya parçalı et yemeklerinin haftada en fazla bir kez planlanmasını istemiştir. $\mathrm{Bu}$ nedenle söz konusu yemeklerin haftalık çıkış sıklıkları kurum isteğine bağlı olarak sınırlandırılmıştır:

$\sum_{j}^{j+4}\left(\sum_{i \in \text { benzer }} A_{i j}\right) \leq 1, \quad j=1,6,11,16$

$\sum_{j}^{j+2}\left(\sum_{i \in \text { benzer }} A_{i j}\right) \leq 1, \quad j=21$

Temel model oluşturulduktan sonra senaryo analizleri yapılmış ve bazı yemek kategorilerinin sunumunda aynı hafta içerisinde aşırı sıklık olabileceği tespit edilmiştir. $\mathrm{Bu}$ nedenle bu tür durumlarla karşılaşılabilecek yemeklerin aynı hafta içerisindeki planlama sıklığına ilişkin kısıtlar geliştirilmiştir.

Benzer yemeklerin peş peşe çıkmasını engelleyici kisitlar: Yemek seçiminde menü örüntüsü açısından yemekler birbirini izleyen günler itibariyle de çeşitlilik göstermeli sık tekrarlardan kaçınılmalıdır [16].

$\sum_{j}^{j+1}\left(\sum_{i \in \text { benzer }} A_{i j}\right) \leq 1 j=1 \ldots$ toplam -1

Excel Makro ile bütünleşik çalışan kısıtlar: Kurum Aşure Ayı'na özel yılda bir defa aşure tatlısı, 18 Mart Çanakkale Deniz Zaferi ve Şehitleri Anma Günü'ne özel olarak buğday çorbası ve üzüm hoşafi sunmaktadır. Aşure ayı içerisinde olunup olunmadığ ve 18 Mart tarihinin iş gününe denk gelip gelmediği bilgileri kullanıcı arayüzünden matematiksel programlama modeline gönderilmektedir.

Aşure Ayı'na özel aşure sunma kısıdl:

$\sum_{j=1}^{t o p} \mathrm{~A}(\mathrm{a}, j)=\left\{\begin{array}{lr}1, & \text { ay }=\text { aşure ayl } \\ 0, & \text { aksi halde }\end{array}\right\}$

18 Mart'a özel buğday çorbası (bc) sunma kısıtları: 


$$
\mathrm{A}(\mathrm{bc}, j)=\left\{\begin{array}{ll}
1, & j=\text { agun } \\
0, & \text { aksi halde }
\end{array}\right\}
$$

Kurum aybaşında alacağı karara göre o ay içerisinde doğrudan alım malzemesi içeren yemeklere yer vermek isteyebilmektedir. $\mathrm{Bu}$ nedenle planlama yapılması istenen ay içerisinde doğrudan alım yapılıp yapılmayacağı bilgisi kullanıcı ara yüzünden matematiksel programlamaya aktarilıp 27 nolu ifade ile ifade edilen kısıtlar ile dikkate alınmaktadır:

$\sum_{j=1}^{\text {top }}\left(\sum_{i \in \text { dalim }} A_{i j}\right)=$

$$
\left\{\begin{array}{lr}
1, & \text { doğrudan alım durumu } \\
0, & \text { aksi halde }
\end{array}\right\}
$$

İfade 27, kurumda kabak tatlisı, ciğer ve mantı için aynen kullanılmıştır. Hindi yemeği için ise doğrudan alım durumunda söz konusu ay içerisinde birden fazla planlamaya izin verecek şekilde düzenlenme yapılmıştır. Ön hazırlık gerektiren yemeklerin çılkamadı̆̆ durumlarla ilgili kssitlar: Toplu beslenme sistemlerinde iki gün veya daha uzun süren tatillerden sonraki iş günlerinde ön hazırlık gerektiren yemeklerin sunumu yapılamamaktadır. Bu nedenle bu durumu dikkate alan ek bir kısıda ihtiyaç duyulmuştur:

$\sum_{i \in o n}\left(A_{i j}\right)=0 j=t d$

Ön hazırlık gerektiren yemeklerden komposto uzun süren tatil dönüşlerinde sunulması mümkün olmayan yemeklerdendir. Ancak 18 Mart tarihi tatil dönüşüne denk gelse bile bu tarihe özel olarak üzüm kompostosu sunulmak istenmektedir:

$\mathrm{A}(u h, j)=\left\{\begin{array}{rr}1,((j=\text { agun }) \vee(\text { agun }=t d)) \\ 0, & \text { aksi halde }\end{array}\right\}$

Mevsimsel sıklık kısıtları: Hava değișimi tüketicilerin yiyecek tercihini etkiler. Soğuk havalarda daha sıcak, enerjisi yüksek yiyeceklere ağırlık verilirken; sıcak havalarda taze, soğuk ve çiğ yiyeceklere ağırlık verilerek menüler oluşturulmalıdır [5]. Bu nedenle mevsimlere bağlı olarak çorbaların, şerbetli tatlıların, balık ve turşuların planlama sıklığına sınırlama getiren kısıtlara ihtiyaç duyulmuştur:

$\sum_{j=1}^{t o p}\left(\sum_{i \in y h} A_{i j}\right) \leq p s \quad \forall m e v$,

Aylık siklık kisıtları: Sağlıklı yaşam koşullarını farklı besinlerle sağlamak için yemeklerin ay içerisindeki çıkış sıklıklarına sınırlama getirilmelidir. Bu durumu ifade eden kısıt ifade 31'de verildiği gibidir:

$\sum_{j=1}^{t o p}\left(\sum_{i \in y h} A_{i j}\right) \geq p s \quad \forall a y$,

Yukarıda ifade edilen kısitlarla model oluşturulduktan sonra senaryo analizleri yapılmış ve anket sonuçlarındaki belirsizliğe bağlı olarak bazı yemek kategorilerinin sunumunda aşırı sıklık olabileceği tespit edilmiştir. $\mathrm{Bu}$ nedenle anket sonuçlarındaki belirsizliklere karşı proaktif bir tutum sergilenerek tüm yemek kategorilerine üst sınır getirilmesine karar verilmiştir. Bu durum eşitlik 29 ile ifade edilmiştir:

$\sum_{j=1}^{\text {toplam }}\left(\sum_{i \in y h} A_{i j}\right) \leq p s, \forall a y$,

(288 * işgünü) adet karar değişkeni, 2880 adet parametre ve 16 adet değişken kullanılarak matematiksel programlama modeli tasarlanmış ve LINGO 14 cebirsel modelleme yazılımı kullanılarak kodlanmıştır. Kodun uzunluğu 1700 satır civarında olduğundan burada yer verilememiștir.

\section{3. ÖRNEK UYGULAMA (CASE STUDY)}

Menü planlama çalışmasında karar destek sistemi kullanmanın tecrübeye dayalı klasik yönteme göre sağladığı avantajları ve performanstaki iyileștirmeleri ölçebilmek amacıyla karar destek sistemi 2013 yılının verileri kullanılarak 12 ay için çalıştırılmış ve sonuçlar Tablo 2'de sunulmuştur.

Tablo 2. 2013 y1lı için karşılaştırma tablosu

\begin{tabular}{|c|c|c|c|}
\hline \multicolumn{4}{|c|}{ Planlama sıklıkları } \\
\hline & \multicolumn{2}{|c|}{$\begin{array}{l}\text { Klasik Yöntemle } \\
\text { Sağlanamayan Gün } \\
\text { Sayısı }\end{array}$} & $\begin{array}{l}\text { Karar Destek Sistemiyle } \\
\text { Sağlanamayan Gün } \\
\text { Sayıs }\end{array}$ \\
\hline 1. Kap & \multicolumn{2}{|c|}{26} & 0 \\
\hline 2. Kap & \multicolumn{2}{|r|}{139} & 0 \\
\hline 3. Kap & \multicolumn{2}{|r|}{175} & 0 \\
\hline 4. Kap & \multicolumn{2}{|r|}{154} & 0 \\
\hline \multicolumn{4}{|c|}{ Tatil dönüşlerinde çıkamayacak yemek kısıdı } \\
\hline & \multicolumn{2}{|c|}{$\begin{array}{l}\text { Klasik Yöntemle } \\
\text { Să̆lanamayan Gün } \\
\text { Sayısı }\end{array}$} & $\begin{array}{c}\text { Karar Destek Sistemiyle } \\
\text { Sağlanamayan Gün } \\
\text { Sayıs }\end{array}$ \\
\hline 1. Kap & \multicolumn{2}{|r|}{27} & 0 \\
\hline 2. Kap & \multicolumn{2}{|r|}{0} & 0 \\
\hline 3. Kap & \multicolumn{2}{|r|}{3} & 0 \\
\hline 4. Kap & \multicolumn{2}{|r|}{0} & 0 \\
\hline \multicolumn{4}{|c|}{ Benzer yemekleri peş peşe planlayamama kısıdı } \\
\hline & & $\begin{array}{l}\text { Klasik Yöntemle } \\
\text { Sağlanamayan } \\
\text { Gün Sayısı }\end{array}$ & $\begin{array}{c}\text { Karar Destek Sistemiyle } \\
\text { Sağlanamayan Gün } \\
\text { Sayıs }\end{array}$ \\
\hline \multicolumn{2}{|l|}{ Sebzeler } & 18 & 0 \\
\hline \multicolumn{2}{|c|}{ Makarnalar } & 8 & 0 \\
\hline \multicolumn{2}{|l|}{ Pilavlar } & 10 & 0 \\
\hline \multicolumn{2}{|l|}{ Çorbalar } & 24 & 0 \\
\hline \multicolumn{2}{|l|}{ Salatalar } & 12 & 0 \\
\hline \multicolumn{2}{|l|}{ Meyveler } & 62 & 0 \\
\hline \multicolumn{2}{|l|}{ Tatlilar } & 8 & 0 \\
\hline \multicolumn{2}{|l|}{$\begin{array}{l}\text { Yoğurt ve } \\
\text { Türevleri }\end{array}$} & 48 & 0 \\
\hline \multicolumn{4}{|c|}{ Özel kısıtlar } \\
\hline \multicolumn{4}{|c|}{\begin{tabular}{c|c|c} 
& $\begin{array}{c}\text { Klasik Yöntemle } \\
\text { Sağlanamayan } \\
\text { Gün Saylsı }\end{array}$ & $\begin{array}{c}\text { Karar Destek Sistemiyle } \\
\text { Sağlanamayan Gün }\end{array}$ \\
\end{tabular}} \\
\hline \multicolumn{2}{|c|}{$\begin{array}{l}\text { Birlikte } \\
\text { Sunulamama }\end{array}$} & 19 & 0 \\
\hline \multicolumn{2}{|l|}{$\begin{array}{l}\text { Kivam } \\
\text { Uyumu }\end{array}$} & 48 & 0 \\
\hline \multicolumn{2}{|c|}{ Renk Uyumu } & 4 & 0 \\
\hline \multicolumn{2}{|c|}{$\begin{array}{l}\text { Mevsimsellik } \\
\text { Etkisi }\end{array}$} & 34 & 0 \\
\hline
\end{tabular}
(Comparative results for 2013) 
Tablodan da anlaşılabileceği gibi geliştirilen karar destek sitemi tüm kısıtları ve amaçları sağlayacak menüleri hatasız olarak oluşturabilmiştir. Aynı dönem için tecrübeye dayalı sistemle oluşturulmuş menüler ayrıntılı olarak analiz edildiğinde ise menü planlama da dikkate alınması gereken amaç ve kısıtların eş zamanlı olarak sağlanamadığı ve planlanan menü listelerinde bir yıl boyunca Tablo 2'de ayrıntılı olarak rapor edildiği üzere, 819 kere hata yapıldığı tespit edilmiştir. Önerilen karar destek sistemi ile 2013 yılı Kasım ayı için oluşturulan aylık menü planı içerisinden 11 - 15 Kasım tarihlerinde sunulması planlanan menü örneği Tablo 3'te sunulmuştur. 2013 yılının tüm ayları için oluşturulan aylık menü listelerinin ayrıntılı haline ise http://web.deu.edu.tr/baykasoglu/deumenu.pdf adresinden erişilebilir.

Tablo 3. Bir haftalık örnek menü listesi ( Sample menu list for a week)

\begin{tabular}{|c|c|}
\hline & $\begin{array}{c}\text { Karar Destek Sistemi İle Elde Edilen } \\
\text { Günlük Menü Listesi }\end{array}$ \\
\hline 1. Gün & $\begin{array}{c}\text { Etli Bezelye; Şehriyeli Pirinç Pilavı; } \\
\text { Yoğurt; Basma Kadayıf }\end{array}$ \\
\hline 2. Gün & $\begin{array}{c}\text { Balık Izgara; Ezogelin Çorbası; Mevsim } \\
\text { Salatası; Sütlü İrmik Tatlısı }\end{array}$ \\
\hline 3. Gün & $\begin{array}{c}\text { Bahçevan Kebabı; Napoliten Soslu } \\
\text { Makarna; Yoğurt; Mandalina }\end{array}$ \\
\hline 4. Gün & $\begin{array}{c}\text { Püreli Dalyan Köfte; Nohutlu Bulgur } \\
\text { Pilavı; Turşu; Yayla Çorbası }\end{array}$ \\
\hline 5. Gün & $\begin{array}{c}\text { Yoğurtlu Bitez Kebabı; Zeytinyağlı } \\
\text { Brokoli; Havuç Salatası; Burma Kadayıf }\end{array}$ \\
\hline
\end{tabular}

\section{SONUÇLAR (CONCLUSIONS)}

$\mathrm{Bu}$ çalışma ile toplu beslenme sistemi uygulayan büyük bir kurumun menü planlama problemi incelenmiş ve etkin menüler oluşturabilmek için matematiksel programlama temelli bir karar destek sistemi geliştirilmiştir.

Önerilen model önce her hangi bir toplu beslenme sisteminde uygulanabilecek özellikleri (temel menü planlama kuralları) sağlayabilecek şekilde tasarlanmış daha sonra da uygulama yapılan kurumun özel ihtiyaçlarını (doğrudan alım durumları, aşure ayına özel aşure tatlısı sunma durumu vb.) karşılayacak şekilde özelleştirilmiştir. Böylece hem diğer toplu beslenme sistemlerinde uygulanması olası olan bir karar destek sistemi elde edilmiş hem de kurumun ihtiyaçları ve kullanıcı alışkanlıkları dikkate alınarak tecrübeye dayalı klasik yöntemden bilgisayar temelli karar destek sistemine geçişin kabullenme süreci hızlandırılmıştır. Bir başka deyişle tasarlanan model ile birlikte başarılı bir değişim yönetimi gerçekleştirilmiştir. Karar destek sistemi kullanılarak elde edilen menü listeleri, programlanan makro yardımıla modelleme bilmeyen kullanıcıların anlayabileceği formata dönüştürülmektedir. Böylece kullanıcının matematiksel modelleme aracına ait sonuç ekranı üzerinden çıktı analizi yapmasına gerek kalmamakta ve her ay için rutin olarak hazırlanan aylık menü listesini planlamak için harcanan süre kısalmaktadır. $\mathrm{Bu}$ durum, çalışanların iş akışında bulunan diğer işlere ayırdığı süreyi artırmakta ve iş akış sürecinde bulunan işlerin tamamında performans artışı sağlamaktadır.

Mevcut çalışma ile birlikte, bilimsel yazında önerilen modellerden [3-12] farklı olarak modelleme yapısı içerisinde, çalışan ve tüketici memnuniyetine yer verilmiş ve menülerin hazırlanmasında aktif rol oynayan çalışanlar ile menü planlama sürecinden etkilenen tüketicilerin istek ve ihtiyaçlarını dikkate alan bir karar destek sistemi tasarlanmıştır. Ayrıca, tasarlanan modelin yıl boyunca bütünleşik çalışabilen bir özelliğe sahip olması yapılan çalışmayı literatürde önerilen modellerden [3-12] ayıran en önemli özelliğidir. Zira önerilen modellerde planlama dönemi değiştikçe uygulayıcılar ya model yapısında oynayarak kısıt ekleyip çıkartmak zorunda kalmakta ya önerilen modelin çözümündeki menü listesinde el ile bazı değişiklikler yapmak zorunda kalmakta ya da her ay için ayrı-ayrı model tasarlanmak zorunda kalınmaktadır. Halbuki bu çalışmada tasarlanan karar destek sisteminde kullanıcinın belirli periyotlarla değişen ihtiyaçları (planlama yapılacak iş günü sayısı, ihale ile belirlenen yiyecek maliyeti vb.) uygun bir kullanıcı arayüzü yardımıyla hesaplanmakta, menü planlama sürecinde dikkate alınması gereken tüm faktörleri eş zamanlı olarak sağlayabilen tek bir model kullanılmakta ve modelin çözümleri yine kullanıcı ara yüzü üzerinden kullanıcının anlayabileceği düzende sunulmaktadır. Böylece uygulayıcı, kullanıcı arayüzünden başka hiçbir program görmediği için güncelleme sirasinda modelde yapilabilecek olası hatalar (yanlış satırı silme, hatalı karakter girişi vb.) önlenmekte ve menü listeleri ek bir düzeltmeye ihtiyaç duyulmadan kullanılabilmektedir. $\mathrm{Bu}$ da tasarlanan karar destek siteminin tasarlayan kişiler dışındaki kullanıcılar tarafından da rahatça kullanılmasina olanak vermektedir.

\section{TEŞEKKÜR (ACKNOWLEDGEMENTS)}

$\mathrm{Bu}$ çalışmanın gerçekleştirilmesi sürecinde bizlere her türlü yardım ve kolaylığı sağlayan başta DEÜ Kantin - Kafeteryalar ve Beslenme Şube Müdürlüğü Birim Sorumlusu Barış Murat Dal olmak üzere tüm kurum çalışanlarına teşekkür ederiz.

\section{KAYNAKLAR (REFERENCES)}

1. Bilici, S. ve Köksal, E., Okul Öncesi ve Okul Çağı Çocuklara Yönelik Beslenme Önerileri ve Menü Programları, Şanlıer N. Sağlık Bak. Yayını, 915, Ankara, 2013.

2. Körpeli, S., Şahin, B. ve Eren, T., "Hedef Programlama ile Menü Planlaması: Bir Örnek Uygulama”, Kırıkale Üniversitesi Sosyal Bilimler Dergisi, Cilt 2, No 1, 121-142, 2012. 
3. Soden, P.M. ve Fletcer, L.R., "Modifying Diets to Satisfy Nutritional Requirements Using Linear Programming", British Journal of Nutrition, No 68, 565-572, 1992.

4. Sklan, D. ve Dariel, I., "Diet Planning for Humans Using Mixed-Integer Linear Programming", British Journal of Nutrition, No 70, 27-35, 1993.

5. Şenol, S., Menü Planlama Sorununa Karma Tamsayılı Programlama Modeli İle Çözüm Önerisi, Y. Lisans Tezi, Süleyman Demirel Üniv., Sosyal Bil. Enstitüsü, 2011.

6. Anderson, A.M. and Earle, M.D., "Diet Planning in The Third World by Linear and Goal Programming", J. of the Operational Research Society, Cilt 34,No 1, 9-16, 1983.

7. Balintfy, J.L., Ross, G.T., Sinha P. ve Zoltners, A.A. , "A Mathematical Programming Systems For Preference and Compability Maximized Menu Planning and Scheduling", Mathematical Programming, No 15, 63-76, 1978.

8. Ediz, A. ve Yağdıran, Y., "Hedef Programlama Tekniği ile Menü Planlaması”, Gazi Üniversitesi İktisadi ve İdari Bilimler Fakültesi Dergisi, Cilt 11, No 1, 45-74, 2009.

9. Mamat, M., Rokhayati, Y., Noor, M. M. ve Mohd İ., "Optimizing Human Diet Problem with Fuzzy Price Using Fuzzy Linear Programming Approach", Pakistan Journal of Nutrition, Cilt 10, No 6, 594-598, 2011.

10. Mamat, M., Zulkifli, N.F., Deraman, S.K., ve Noor, M. M., "Fuzzy Linear Programming
Approach in Balance Diet Planning for Eating Disorder and Disease-related Lifestyle", Applied Mathematical Sciences, Cilt 6, No 103, 51095118, 2012.

11. Oruç, K. O., Güngör, İ., Irmak, S. ve Şenol, S., "Menu Planning with Fuzzy 0-1 Integer Programming", International Burch University 3rd International Symposium on Sustainable Development, Sarajevo, 6-27, 31 May - 01 June 2012.

12. Oruç, K.O., "Bulanık Hedef Programlama İle Menü Planlama", Yönetim ve Ekonomi Araştırmaları Dergisi, No 23, 2014.

13. Şahin, A.E., "Türkiye'de İlköğretim Okulu Müdürlüğünün Bir Meslek Olarak Mevcut Durumu: Bir Delphi Çalışması”, Pamukkale Üniversitesi Eğitim Fakültesi Dergisi, No 26, 125-136, 2009.

14. Şahin, A.E., "İlköğretim Okulu Müdürlerinin Yeterlilikleri”, Kuram ve Uygulamada Eğitim Yönetimi, No 22, 243-260, 2000.

15. Özen, Y., Gül, A., "Sosyal Ve Egitim Bilimleri Araştırmalarında Evren. Örneklem Sorunu", Atatürk Üniversitesi Kazım Karabekir Eğitim Fakültesi Dergisi, No 15, 394-422, 2007.

16. Baş, M., Bilici, S., Bayrak, E. ve Tütüncüoğlu, C., Tam Gün Okullara Yönelik Geliştirilen Menü Modelleri ve Örnek Öğle Yemeği Listeleri, Sağlık Bakanlığı Yayını, 798, Ankara, 2010. 


\section{EK (APPENDIX)}

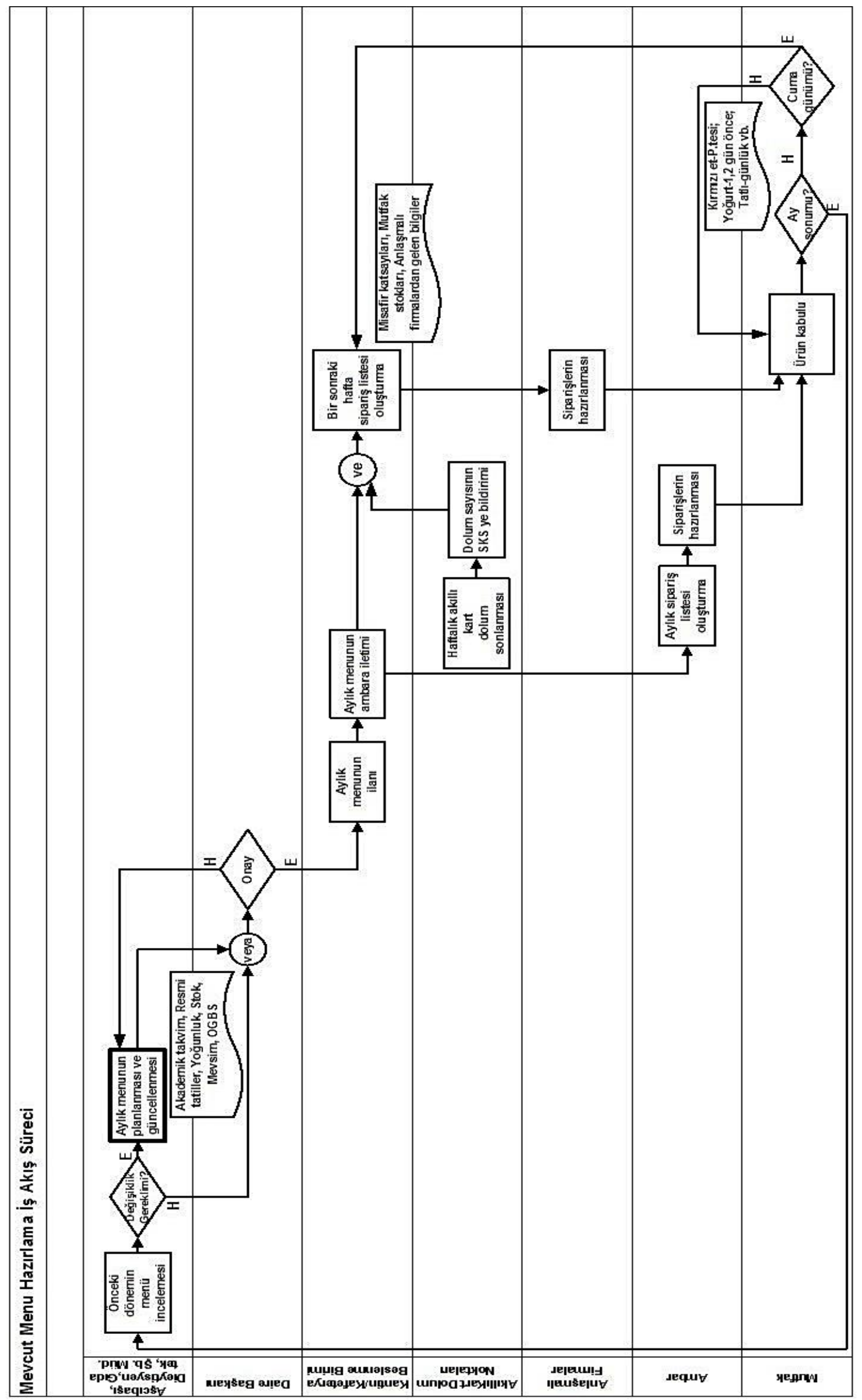

Şekil E1. Mevcut iş akışı ve karar alma süreci (Current workflow and decision making process) 